\section{Gastric necrosis following intragastric balloon placement: urgent sleeve gastrectomy as a rescue and definitive procedure}

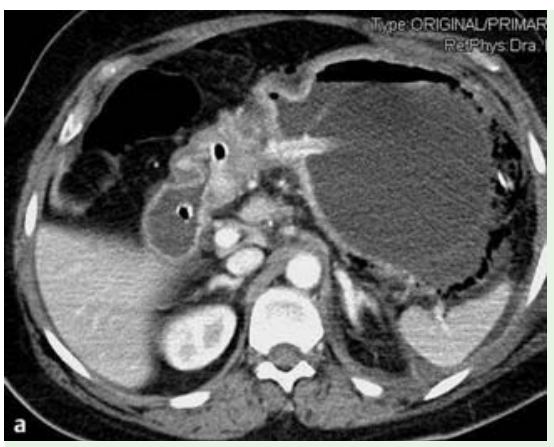

Fig. 1 a Axial computed tomography (CT) image after intravenous contrast agent administration, showing gastric dilatation and wall thickening. b Coronal CT image showing gastric wall thickening with thin linear air bubbles, suggesting gastric necrosis and perforation.
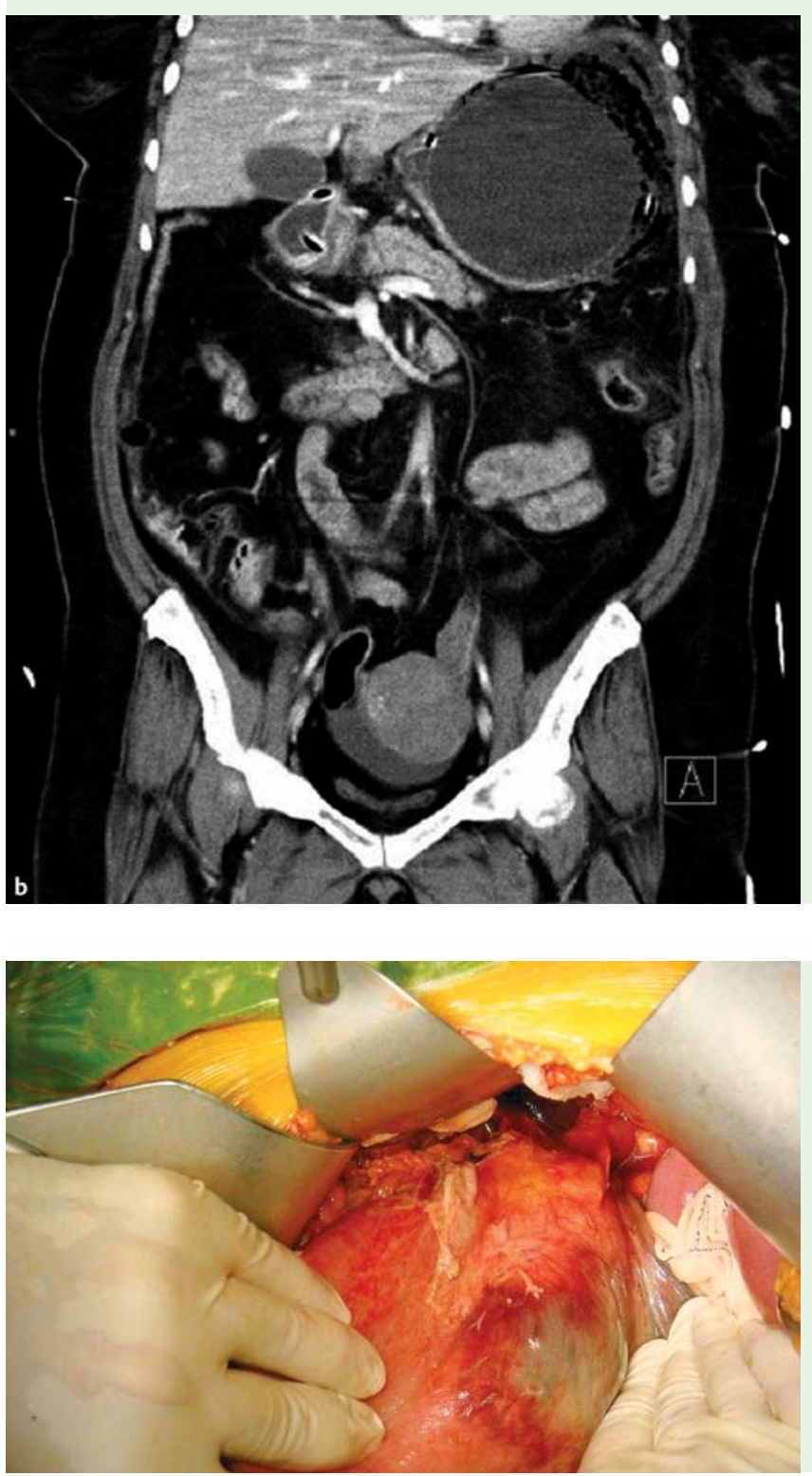

Use of an intragastric balloon (IGB) as a temporary weight-loss procedure in obese patients has become widespread since $1982[1,2]$. We present a case of gastric necrosis following balloon refilling, successfully treated with an urgent vertical sleeve gastrectomy.

A 55-year-old woman with a body mass index (BMI) of $33.6 \mathrm{~kg} / \mathrm{m}^{2}$ had undergone IGB placement (Spatz Adjustable Balloon System; Spatz FGIA Inc., Jericho, New York, USA). After 3 months, the IGB was refilled. The patient came to the emergency unit with vomiting and abdominal pain 34 hours after the IGB was refilled.

On admission, the woman presented with hypotension and tachycardia. A nasogastric tube was inserted, yielding $3 \mathrm{~L}$ of gastric content. After the patient was stabilized, an urgent computed tomography (CT) scan revealed gastric dilatation with wall pneumatosis and signs of perforation ( $\bullet$ Fig. 1$)$.

An urgent laparotomy was carried out. On exploration, gastric necrosis and perforation were confirmed ( $\bullet$ Fig. 2). A vertical sleeve gastrectomy was performed. An intraoperative endoscopy assessed the viability of the remnant esophagogastric junction and gastric mucosae. The patient was discharged from hospital on the postoperative day 15 . The patient was in good condition 6 months after the sleeve gastrectomy, with a BMI of $29.1 \mathrm{~kg} / \mathrm{m}^{2}$.

Since the first IGB placement by Nieben and Harboe in 1982, there has been a steep increase in the number of these procedures as a temporary measure for losing weight [1,2]. Among the major IGB complications reported, several stand out: balloon deflation and migration, intestinal obstruction, and massive gastric dilatation with necrosis and perforation $[3,4]$.

Regarding gastric necrosis in patients with IGB devices, a total of 16 cases have been previously reported. In our case, the perforation was diagnosed 48 hours after refilling the balloon device. There has been only one previous case in which an emergency sleeve gastrectomy was performed as a rescue treatment for gastric fundus necrosis in a patient with gastric banding and a misdiagnosed type II paraesophageal hernia [5].

Endoscopy_UCTN_Code_TTT_1AO_2AN

Competing interests: None 
J. A. Cienfuegos ${ }^{1}$, V. Valentí ${ }^{1}$,

M. Muñoz-Navas ${ }^{2}$, F. Rotellar ${ }^{1}$,

J. Arredondo ${ }^{1}$, M. Herraiz ${ }^{2}$,

F. J. Zozaya-Larequi ${ }^{2}$, F. Martínez

Regueira', G. Frühbeck ${ }^{3}$,

J. L. Hernández-Lizoain ${ }^{1}$

${ }^{1}$ Department of Surgery, University Hospital of Navarra, Pamplona, Spain

2 Service of Gastroenterology, University Hospital of Navarra, Pamplona, Spain

${ }^{3}$ Department of Endocrinology and Nutrition, University Hospital of Navarra, CIBERobn, Pamplona, Spain

\section{References}

1 Nieben OG, Harboe $H$. Intragastric balloon as an artificial bezoar for treatment of obesity. Lancet 1982; 1: $198-199$

2 Negrin Dastis S, Francois E, Deviere J et al. ssIntragastric balloon for weight loss: results in 100 individuals followed for at least 2,5 years. Endoscopy 2009; 41: 575-580

3 Giardello C, Cristiano S, Cerbone MR et al. Gastric perforation in an obese patient with an intragastric balloon, following previous fundoplication. Obes Surg 2003; 13: 658 660

4 Totté E, Hendrickx L, Pauwels M et al. Weight reduction by means of intragastric device: experience with the Bioenterics intragastric balloon. Obes Surg 2001; 11: 519-523

5 Bernante P, Breda C, Zangrandi $F$ et al. Emergency sleeve gastrectomy as a rescue treatment for acute gastric necrosis due to type II paraesophageal hernia in an obese woman with gastric banding. Obes Surg 2008; 18 : $737-741$
Bibliography

DOI http://dx.doi.org/ 10.1055/s-0032-1310074 Endoscopy 2012; 44: E366-E367

(c) Georg Thieme Verlag KG Stuttgart · New York ISSN 0013-726X

\section{Corresponding author} J. A. Cienfuegos, MD, PhD Department of Surgery Clínica Universidad de Navarra Avenida Pío XII 36 31008 Pamplona Spain

Fax: +34-948-296500

fjacien@unav.es 